\title{
DESIGN AND FABRICATION OF PROTOTYPE OF MULTIPURPOSE MACHINE FOR SHEET METAL OPERATIONS
}

\author{
Awez Inamdar ${ }^{1}$, Rahul Gupta ${ }^{2}$, Prasad Kawli ${ }^{3}$, Rohan Malekar ${ }^{4}$ \\ Guided By: Prof. Swapnil Mane \\ ${ }^{I}$ Mechanical Engineering Department Vidyavardhini's College of Engineering and Technology Vasai (W) \\ inamdar.awesb@gmail.com \\ ${ }^{2}$, Mechanical Engineering Department Vidyavardhini's College of Engineering and Technology Vasai (W) \\ rahulgupta0767.rg4@gmail.com \\ ${ }^{3}$ Mechanical Engineering Department Vidyavardhini's College of Engineering and Technology Vasai (W) \\ prasadkawli8@gmail.com \\ ${ }^{4}$ Mechanical Engineering Department Vidyavardhini's College of Engineering and Technology Vasai (W) \\ rohanmalekar242@gmail.com
}

\begin{abstract}
Sheet metal is basically a thin sheet of metal by using several operations. Nowadays it has become one of the most important and fundamental forms in metalworking. [10] the advantage of sheet metal is that it can be bent into variety of desired shapes. Lots of everyday objects are being manufactured using sheet metal. Sheet metal is mainly used for various aerodynamically shaped car bodies, airplane wings, architecture and many other applications. [9] dent removing/rolling, cutting and v-grooving are the most widely used operations in the fabrication industry. The conventional machines could only carry out any of the above operations simultaneously. If these operations can be done on a single machine, it would not only make work quite easy and less tedious but also increases profitability .moreover, conventional machines are often hand operated for small scale industry applications. Also the time taken on these separate machines that is the overall lead time decreases by making them power operated, resulting in lower cost and higher productivity. Our project is to encompass these operations onto a single machine successfully.
\end{abstract}

Keywords: Sheet Metal, Rolling, Cutting, V-Grooving

\begin{tabular}{|ll|}
\hline \multicolumn{2}{|l|}{ NOMENCLATURE } \\
{$[\sigma]$} & Tensile stress $\mathrm{N} / \mathrm{mm}^{2}$ \\
Fs & Shearing stress $\mathrm{N} / \mathrm{mm}^{2}$ \\
$\mathrm{~F}$ & Force N \\
$\mathrm{P}$ & Power KW \\
$\mathrm{T}$ & Torque $\mathrm{N}-\mathrm{mm}$ \\
$\mathrm{S} . \mathrm{F}$. & Service factor \\
$\mathrm{N}$ & speed rpm \\
$\mathrm{i}$ & Reduction ratio \\
$\mathrm{d}$ & diameter of driver $\mathrm{mm}$ \\
$\mathrm{D}$ & diameter of driven $\mathrm{mm}$ \\
$\mathrm{V}$ & speed m/sec \\
$\mu$ & Co-efficient of friction \\
$\mathrm{T}$ & tension in belt $\mathrm{N}$ \\
$\mathrm{Z}$ & no. of teeth \\
$\mathrm{Z}$ & no. of starts \\
$\mathrm{a}$ & center distance $\mathrm{mm}$ \\
$\mathrm{mx}$ & module mm \\
$\mathrm{L}$ & length mm \\
da & Tip diameter mm \\
df & Root diameter mm \\
$\mathrm{p}$ & pitch mm \\
\hline
\end{tabular}

\section{INTRODUCTION}

Today's world requires speed on each and every field. Hence rapidness and quick working are the most important factors. For achieving the same, various machines and the equipment's are manufactured by the man. The engineer is constantly conformed with the challenges of bringing ideas and design in to reality new machine and techniques are being developed continuously to manufacture various products at the cheaper rates and high quality. In the age of automation machine become an integral part of human being. In competition market, everyone strive to increase their production \& reduce cost and time constraints. Sheet metal is basically a thin sheet of metal by using several operations. Nowadays it has become one of the most important and fundamental forms in metalworking. The advantage of sheet metal is that it can be bent into variety of desired shapes. Lots of everyday objects are being manufactured using sheet metal.[10] Sheet metal is mainly used for various aerodynamically shaped car bodies, airplane wings, architecture and many other applications.[9] The increased consumer demand in India from particularly the Automotive, Aerospace, construction and Electronics industry facilitated for manufacturers and suppliers of Sheet Metalworking and related services. The demand for 
Automotive Industries' end product in India has increased by $50 \%$ past 3 years as estimated by Bric. [7]

\subsection{V-Grooving}

In $\mathrm{V}$ - grooving operation, a pair of punch with a desired angle of bends causes the metal strip or sheet into a wedge shaped groove as it is passed through the die. The bend angle is given as per the requirement of the operation. The deformation is achieved as the contact forces by the punch causes a sufficiently large bending moment to make the desired groove. Plane strain conditions are established in the center of the sheet if it width is more than 10 times its thickness. The required die set according to the type on groove required is installed on the load bearing shaft and the nut bolts are tightened. The required gap between the two grooving dies is adjusted with the help of actuation gears. Lesser the gap thinner the sheet can be grooved. The shape of the grooves depends upon the formed shape of the male and female dies. For having grooving operation of thicker sheets, the gap between the two die is increased. When the handle is rotated the gear installed on the handle shaft linked with the grooving gear, it rotates one die gear. The male die rotates over the female die and the sheet advances through them having groove on it. [3]

\subsection{Straight Cutting}

Straight cutting of sheet metal with shearing can be comparatively easy and can have long life if maintained properly. A metal sheet is passed through two cutting rollers having a sharp cutting edge. For easy and comfortable cutting, the edges should be sharpened regularly. The alignment of two blades is also an important factor in order to have perfect cutting. When machine starts to give poor cuts it is likely that the cutting edges have become blunt. Shear cutters are nothing but cutting tools and like any other cutting tool the cutting angle and finishing play an important role in the performance of cutting tool. Lower blades are sharpened and kept to the same specifications as upper blades are kept. The blade should be sharpened at an angle of eight degrees and must be straight along the entire length so the clearance between it and the upper blade is uniform. A poor cut can result if proper and uniform clearance is not provided.. The extremely fine edge is ideal for producing clean, sharp cuts on soft plastics. This sharp edge tends to dull more quickly and require more frequent sharpening.[8]

\subsection{Dent Removing}

The Dent is physical plastic deformation on sheet metal and look like hill and valley type pattern on sheet surface. This dent creates problem while manufacturing and with the surface finish of the sheet metal. Also after completing sheet metal job if minor dents remain, it'd be visible after painting or plating due to which the complete job would be rejected. So to remove these type of dents, we made an arrangement to remove dent from sheet metal by rolling operation.

\section{GENERAL PROCEDURE IN MACHINE DESIGN}

The general steps to be followed in designing the machine are as follows:-

1. Preparation of a statement of the problem indicating the purpose of the machine.

2. Selection of groups of mechanism for the desire motion.

3. Calculation of the force and energy on each machine member.

4. Selection of material.

5. Determining the size of component drawing and sending for Manufacturing.

6. Preparation of component drawing and sending for manufacture.

7. Manufacturing and assembling the machine.

8. Testing of the machine and for functioning

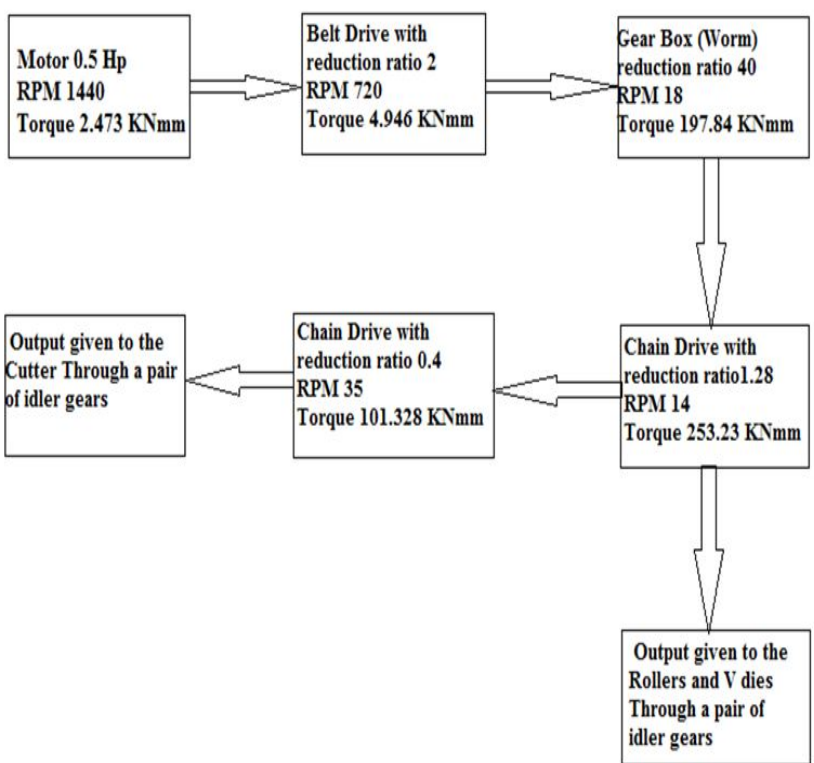

Fig.1. Flow Chart of Working of the Machine.

As seen from above, in order to obtain necessary speed and torque, speed reducers are used from the motor, a torque of $253 \mathrm{KN}$ is required for rolling and $\mathrm{V}$-grooving for a given selection of sample sheet of Mild Steel of thickness $2 \mathrm{~mm}$. Hence a worm gear drive is used for this purpose. For cutting operation torque is transmitted via chain drive.

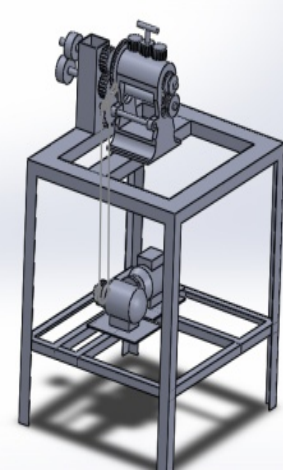

Fig.2.a. Assembly of the actual prototype. 


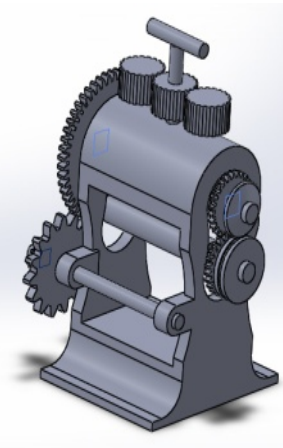

Fig.2.b. Model of the multi-operation mechanism.

\section{MATERIAL SELECTION}

The proper selection of material for the different part of a machine is the main objective in the fabrication of machine. For a design engineer it is must that he be familiar with the desired properties of the materials for the given purpose. For any engineering purpose, following are the factors that are ought to be taken into consideration;

1. Material Availability.

2. Suitability in service conditions.

3. Cost of the material.

4. Physical and chemical characteristics of the material.

5. Mechanical properties of the material.

\begin{tabular}{|l|l|l|}
\hline $\begin{array}{l}\text { Sr } \\
\text { No. }\end{array}$ & Part Name & Material \\
\hline 1 & Frame & Mild Steel \\
\hline 2 & Chain Drive & Standard Component \\
\hline 3 & $\begin{array}{l}0.75 \quad \text { hp } 1200 \mathrm{rpm} \\
\text { Motor }\end{array}$ & Standard Component \\
\hline 4 & Gear Box & Mild Steel \\
\hline 5 & Pulley & Cast Iron \\
\hline 6 & Gear & Medium C Steel \\
\hline 7 & Cutter & WPS \\
\hline 8 & V-Grooving Die & Mild Steel \\
\hline
\end{tabular}

\section{APPLICATIONS}

Sheet metal operations are used in jewelry industries, texture forming industries, interior decorations and many such small scale industries. With our proposed machine these operations can be carried out on a single machine at a cost approximately equal to the conventional machines.

\section{RESULTS AND DISCUSSION}

For designing the system, motor is kept as primary constraint. Accordingly the design calculations for all the necessary components are done. Although we've designed the system with the necessary safety factors, these are theoretical values that we've obtained for the components. But after actual market research for the availability of the components, we may or may not be able to procure the components of our desired dimensions. In such case, standard components with approximate conformance with our desired values would be procured and corresponding modifications would be done.

\section{CONCLUSION}

In this project we have aimed to reduce workload, space, time, money associated with the Cutting, V-Grooving and Dent Removing operations by incorporating them in a single, multipurpose machine. As all the operations can be performed at one place and small area this machine will be very useful in small scale industries. We have used only vgrooving die in this machine, but we can attach any die as per our convenience and can perform any type grooving on this machine. Thus this machine performs all three task of Cutting, V-grooving, Dent removing properly.

\section{ACKNOWLEDGEMENTS}

We wish to place on record, our sincere gratitude to Prof. Swapnil R Mane, Vidhyavardhini's college of Engineering and Technology, Vasai (W), as being our project guide ,gave us all the knowledge, inspiration, guidance and spontaneous help required for our project. Their involvement in the project has given us constant encouragement. Our special thanks to Prof. V.D.Patel, the HOD of Mechanical engineering department for his constant support and encouragement for this project. We would like to thank Prof. A.J.Chaudhari, the project coordinator for supporting us throughout our endeavor. We humbly thank all our professors and staff members of the Mechanical Department of Vidhyavardhini's College of Engineering and Technology, for helping us and providing excellent facilities for completing our project. Last but not the least we would also like to thank all our friends who helped us at every moment of time.

\section{REFERENCES}

[1]. PSG college of technology, Design data book, Coimbatore, 2007

[2]. Hajra and Choudhary, Elements of workshop technology, India, 2003

[3]. Faizahmed, A., Riyajhusen, K. D., Tosif, I. K., Sawood, S. M., \& Wasim, L. P. (2015)

[4]. Model of Multipurpose Sheet Metal Processing Machine 3(01), 1305-1306.

[5]. Liewald, M., Bolay, C., \& Thullner, S. (2013). Shear cutting and counter shear cutting of sandwich materials. Journal of ManufacturingProcesses. http://doi.org/10.1016/j.jmapro.2013.03.001

[6]. Company. (n.d.). Optibelt Technical Manual for V belt Drive

[7]. Punjab college of engineering and technology Research scholar, Methods to improve mechanical properties EN31(high carbon steel)and D3(high carbon high chromium steel materials)

[8]. www.bricpartner.com/en/Nd/i/more/Sheet+metal+wor king+technology+opportunities + in + india/idn/2126

[9]. www.antaresinc.com

[10]. wikipedia.org

[11]. www.spaceclaim.com 